\title{
LIVE MUSIC PERFORMANCES AND THE INTERNET OF THINGS
}

\author{
Jennifer L. Breese, Penn State University, jzb545@psu.edu \\ Mark A. Fox, Indiana University South Bend, mfox1@iusb.edu \\ Ganesh Vaidyanathan, Roosevelt University, gvaidyanathan@roosevelt.edu
}

\begin{abstract}
While the term Internet of Things (IoT) has become commonplace in both the vernacular of technologists and consumers alike the Internet of Musical Things (IoMusT) is an emerging field that promises to expand the landscape of music technologies. The internet of things provides additional possibilities for live music performances in particular. These possibilities can potentially increase markets for live music or substitute for traditional live performances during times when audience members may be unwilling to attend traditional concerts (for example, in a pandemic). Additionally, the technology could provide more interactive experiences for concert goers, affordable attendance options to a broader audience, and provide additional income streams for performers. We provide a model of critical considerations for integrating the internet of things with live concerts. The model framework has four parts: audience/musician interactions; technology; business models; and privacy and legal considerations.
\end{abstract}

Keywords: Concerts, Music, Internet of Musical Things, Internet of Things, Virtual Concerts, Live Streaming

\section{INTRODUCTION AND A CONCEPTUAL MODEL OF THE INTERNET OF THINGS AND CONCERTS}

While the term Internet of Things (IoT) has become commonplace in both the vernacular of technologists and consumers alike the Internet of Musical Things (IoMusT) is an emerging field that promises to expand the landscape of music technologies (Turchet et al, 2018). The purpose of this paper is to explore the possibilities of the IoMusT and the intersection with live musical performances. Live music has become increasingly important for musicians as their income from other sources (in particular from sales of pre-recorded music) have declined due to piracy and the availability of music in other formats and outlets, e.g., streaming and downloads. The average price of tickets at the top 100 North American tours increased 55\% from 2009 to 2019 (Steele, 2019). However, the revenues from live events makes up nearly half of the total profits of musicians in recent years (Messenger, 2018). More recently, the COVID-19 pandemic led to widespread cancellations of traditional concerts where a live band performs simultaneously to an in-person audience. As a result musicians increasingly sought other ways to connect with their audiences that did not involve the risks associated with performing at traditional, crowded concert venues.

We conceptualize a three-part model of the concert performances that involves the Internet of Musical Things:

1. Audience/musician interactions: what are the different ways in which musicians and audiences interact?

2. Technology usage: how can we use technology to facilitate audience/musician interactions, while monetizing these interactions?

3. Business models: how can musicians monetize their performances using the Internet of Things (IoT)?

4. Privacy and legal considerations: what additional privacy and legal considerations are worthy of consideration beyond those that are normally considered for in-person concerts?

These four components inevitably influence one another. For example, audience/musician interactions will be influenced by (and influence) the technologies used to facilitate those interactions as well as the possibilities for the business models that one can adopt to monetize audience/musician interactions. Next, we discuss the key features of each part of our conceptual model. In doing so we draw upon existing literature in the fields of cultural economics, information technology, and business law. We also use examples of emerging practices.

\section{AUDIENCE/MUSICIAN INTERACTIONS}

For fans of musicians, one of the most obvious benefits of attending a live concert is sharing this experience, contemporaneously with a community of similarly devoted individuals. This feature of concerts has been called "liveness" (Westgate, 2020). Interestingly, one study demonstrated that the musicians performed better when they 


\section{Issues in Information Systems}

Volume 21, Issue 3, pp. 179-188, 2020

interacted with their audience (Moelants et al., 2012). There is also an element of hero-worship in attending live concerts as many fans regard their musical heroes as having special musical or songwriting abilities; not to mention that many musicians are typically regarded as celebrities (Kulczynski et al., 2016). Concerts also allow fans insights into a band's music that they may not otherwise gain, e.g., when musicians introduce songs with stories about what inspired them (Black et al., 2007).

There are various disadvantages to attending live concerts. Earl (2001) categorizes these disadvantages as being associated with three types of costs: economic costs, sensory costs, and time-related costs.

- Economic costs of attending live concerts include: the costs of purchasing tickets, travel to the venue, parking, childcare costs, and the inflated food and beverage prices at venues.

- Sensory costs of attending concerts include: having undesirable views or views obstructed by other patrons (who may decide to dance or use their cellphones to record the concert); being exposed to other fans who illicitly smoke cigarettes or weed. The audio quality at concerts is typically lower than that provided by listening to, say, a digital recording, and we may be distracted by other patrons who talk during the concert.

- Time-related costs of attending concerts include: the time taken to travel to and from the venue itself; time spent waiting in line to enter (or to buy food and beverages); and time spent waiting for a concert to start and to exit the venue after the performance.

These costs act to influence whether fans attend concerts at all, or-if they do attend-which venues they will go to, where they will sit, and which performances they are willing to see (Black et al., 2007). The Internet of Musical Things (IoMusT) provides opportunities for fans to reduce or eliminate some of these costs.

The focus of this paper is the traditional live concert, where a musician or group performs for an audience. There are various possibilities for how this can occur, such as:

- The traditional model whereby musicians are performing to an audience that is present at the same time and venue.

- Live remote attendance, where some or all of the audience can view and/or listen to the performance remotely (either in real time or delayed) using technology (their TV, computer, or mobile device). In this model the venue for the music may be a traditional concert venue or a virtual venue (such as a gaming platform).

- The hologram model where the musician is not present and is presented in virtual form, typically to an audience that is still alive. This has occurred with holograms of popular performers such as Tupac Shakur, Elvis, Roy Orbison, Amy Winehouse, and Whitney Houston.

The IoT has presented many new possibilities for live music performances with regard to both the production of online live concerts and the adoption of new business models. Next, we discuss these possibilities.

\section{TECHNOLOGY}

With respect to technology, the key issue for our research is: how can the IoMusT influence performance and the experience of attending a concert? In 2020, during the Covid-19 pandemic, many musicians made use of technology to stay connected to fans and to provide live performances that were often free to fans. Musicians did this as the necessity for social distancing made it unsafe to perform in traditional live settings. National Public Radio (NPR), among others, posted extensive compilations to help music lovers locate these live virtual concerts and live streams (Gotrich, 2020). Touted as a way to bring joy, connect with fans, and raise funds for charity, a variety of musicians and institutions are offering these 'new' live performances; however, some lesser known artists have been doing this for years (Billboard, 2020). The pandemic resulted in the music industry moving further and faster on the trajectory it was already following.

Examples of using Augmented Reality (AR) and Virtual Reality (VR) described as, "two sides of the same coin," by Gandolfi (2018) both have the goal of extending the sensory experience mediating reality through technology (p. 545) provide additional opportunities for live music performances. Virtual Reality is associated with personal computers and digital realms; providing experiences that are difficult in real-life. Augmented Reality seeks to improve actual elements through technology (Gandolfi, 2018); the objective is to "see and experience the real world mixed with 


\section{Issues in Information Systems}

Volume 21, Issue 3, pp. 179-188, 2020

various virtual objects, without losing the sense of reality” (Persefoni \& Tsinakos, 2015, p. 45). Developments in these immersive technologies allow for a range of interdisciplinary applications (Dieck, 2019). Elvezio et al. (2018) presented hybrid user interfaces supporting immersive exploration of music content in VR and AR. Participants will be able to use an AR/VR HWD (head worn display) and/or a multi-touch display to navigate a space of genres, artists, albums, and songs to interact with 3D images separating themselves from reality and each other. This example demonstrates possibilities for live music performances; but the authors did not delve further into that arena.

Overlaying computer-generated information on the real world augmenting reality (AR) amplifies human perception and cognition. This burgeoning field requires knowledge of multiple disciplines, including computer vision, computer graphics, and human-computer interaction (Schmalstieg \& Höllerer, 2016). A pertinent debate is whether applications such as these can provide users with a truly 'social' immersive experience in the performance genre and the comfort level of interaction of participants (Baker, 2017). In 2016, Live Nation teamed with Citi and NextVR to broadcast dozens of concerts in VR; artists performed live in venues, for example, some artists performed in zoos with additional footage of the artist touring the zoo to bring closeness of relationship between the artist and the participants (Lab, 2017).

Virtual Reality use in gaming is now common, including live performances within gaming platforms. None have been as successful as games like Fortnite (Hood et al., 2020). Rubin (2019) recounted the Marshmello (DJ) event on Fortnite that came as close to VR as it could get without actually being VR, the event did not require headsets and the dancing that occurred with avatars was a good representation of reality without actual player movement. The event was an immersive community musical experience (Rubin, 2019). Technology is taking music in varied directions providing an opening to new audiences and arguably immersive experiences (Rogers, 2020).

Holograms are an example of Augmented Reality (Gandolfi, 2018). The hologram performance of Tupac Shakur at Cochella 2012, some fifteen years after his death, created an intersection of new technological possibilities in music entertainment (Drecolias, 2014; Tsukayama, 2012). The performance significantly impacted record sales with Tupac's greatest hits album returning to the top of The Billboard Top 200 for the first time in a decade (Caulfield, 2012). One issue with holograms, at least with deceased artists, has been that some fans view this as distasteful or not being a 'real' live experience.

On March, 112008 TwitchTV's top streamer 'Ninja' and rappers Drake and Travis Scott teamed up in the video game Fortnite, garnering hundreds of thousands of views (Mallin, 2018). Subsequently, in late April 2020 Travis Scott collaborated with Fortnite developer Epic Games for an in-game live event, Astronomical. This was viewed by twelve million concurrent viewers, their largest in-game event proving its standing as a social platform as well as a game (Shanley, 2020). This event resulted in a ripple of publicity and accolades from gamers and non-gamers alike (Shanley, 2020). Fortnite is immensely popular particularly because of its 'free' and open platform. The game creates a revenue stream through a charge for 'skins or costumes' and purchased additions to the game (Ganti, 2020).

Apps like Whova and their competitors including CrowdCompass, Socio, and EventMobi provide interaction between audience members, as well as provide interactive platforms to professional conferences. Participants can engage in activities such as welcoming each other, asking ice breaker questions, network, and provide speaker questions all the while climbing a leaderboard and collecting badges (Tong et al., 2016). These types of applications could have significant possibilities for live music, but it appears that this transfer has yet to be pursued.

For years, Stageit has been a forum for lesser known artists (Billboard, 2020) and was on a downturn prior to the crisis; early investors predicted a push from video games to concerts that did not come (Greenburg, 2020). However, livestream platforms have become increasingly popular while much of the population was under stay-at-home orders. Twitch, the largest of these platforms was acquired by Amazon in 2014 and changed direction from solely a video game watching mainstay prior to the crisis (Khalid, 2020). As Doron Nir, CEO of StreamElements, observes: "One of the biggest trends in livestreaming during social distancing has been the massive influx of musicians and other performing artists who have been leveraging the medium to connect with their fans" (as cited in Khalid, 2020). Livestreaming does not offer artists a clear path to monetization; however, a partnership between Bandsintown and Twitch offers an example through the creation of premium artist channels for fees and tips. The sustainability and ability to raise significant revenue through this partnership remains to be seen. A review of popular literature reporting 


\section{Issues in Information Systems}

Volume 21, Issue 3, pp. 179-188, 2020

on Livestreaming seems to indicate larger established companies acquiring smaller Livestreaming platforms. Mixer, purchased by Microsoft in 2016, is a subscription platform where participants can earn 'embers' (virtual currency) toward perks and additional services. Fortnite star Ninja moved solely to this platform which brighter a lot of followers and should allow them to keep growing to compete with twitch (Webb, 2019).

While online sites to explore relatively unknown artists have proliferated for years, this new era seems to be pushing the online aspect further faster among artists with large existing fanbases. All of the larger well-known social media platforms have development "Live" versions: Facebook Live, Youtube Live, Instagram Live are examples of platforms for popular artists and are beginning to work through sustainable monetization models.

\section{BUSINESS MODELS}

The Internet of Things (IoT) opens up various possibilities for how musicians monetize concerts. We can conceptualize concerts as a series of related events: practice, staging, soundcheck, pre-concert, concert, encore, post concert events, and musicians leaving the venue. Each of these steps can be monetized in different ways, or in ways that offer consumers an overall "package" experience. Generally speaking, new business models have used opportunities created by the advent of the Internet. Internet business models have incorporated concert sponsorship efforts, tiered pricing of hits and non-hits, pricing based on traditional models, busking, and paying for memorabilia or mementos.

Traditionally, free music has been made available to consumers through what is known as the broadcasting model that includes television and radio broadcasting where the broadcaster generates revenue through advertising. More recently, sites such as YouTube operate largely using the broadcasting model. Fox (2004) proposed a business model based on the broadcasting model whereby fans can listen to or download directly from the websites of music companies. Those websites generate revenue through advertising, merchandise sales, and commissions on concert tickets (Fox, 2004). Subscription services, where consumers pay a monthly fee to access music of their choice, are also very attractive due to music being readily available and easy to download (Fox, 2004). As we have seen Amazon, Apple, Google, Idagio, LiveX, Pandora, SiriusXM, Spotify, and YouTube have profited by adopting this business model. Such subscription models act as intermediaries in the digital distribution of music. However, such an intermediary structure with successive oligopolistic segments can lead to higher consumer prices through double marginalization (Hviid et al., 2018). Free concerts are made possible online by the use of sponsorship or advertising. Some artists also provide free online concerts that provide consumers with the option of tipping using a virtual tip jar.

Streaming of concerts is the most basic means of using the Internet to reach fans. Such concerts can be either live or pre-recorded. Live concerts offer an immediacy of experience and more social cache than viewing pre-recorded concerts. Both Facebook and Youtube, who already have millions of users and built in social networking functions have been used for streaming concerts. While artists have been giving their work away freely, during the pandemic, monetization is an inevitable part of industry. For example, in April 2020 Facebook announced the release of a fee for concert streaming service (Gartenberg, 2020). Some performers (or their estates) have streamed pre-recorded concerts that start at a predetermined time so that fans can contemporaneously share in the experience. For example, the estate of Prince released a 1985 recording of Prince and The Revolution on Youtube that fans could watch on May 14th, starting at 8 p.m. ET. This allowed fans to simultaneously interact (in the comments section) while experiencing the concert and share their experience (Martoccio, 2020). Once the "live" stream was over fans could then view the concert recording.

The concert business model has been very popular over the years. Traditional concerts typically adopt a tiered pricing structure for seats, with more desirable seating priced at a premium compared to seating that has poorer views and is further away from the performing musicians. Such a model has possibilities for virtual attendance--with more attractive seating locations being priced at a premium. The potential monetization options mentioned above may be limited by artistic integrity. Having said that, musicians themselves often realize there is a trade off between giving an audience what they want (for example, playing their most popular songs) versus what an artist may be interested in (for example, exposing the audience to newer or less well-known songs). In terms of popular music, one area where monetization may be more compelling for both parties is in encores. For example, fans can sometimes vote for which 


\section{Issues in Information Systems}

Volume 21, Issue 3, pp. 179-188, 2020

song they would like to hear at a concert, or to see performed during an encore (Webster, 2012). To maintain some degree of artistic integrity musicians may limit fan voting choices to a few songs. For example, the Rolling Stones invited fans to vote between four songs, one of which they performed, during their 2019 North American tour (Shah, 2019).

The use of mobile Internet and social media has allowed fans to enjoy concerts, connect with each other, tweet and share their opinions, and access current information even during live concerts. Such interactions tend to influence music performers, fans, composers, and technologists (Bennett, 2012). Fans have increasing influence in shaping the business models (Byam, 2007). Typical network structures of the music industry include fans as customers, companies and individuals who earn money by creating new songs, concerts, recordings, compositions, and the organizations who represent musicians. As a result, new business models have appeared in the music industry.

Financing to create music has also been transformed through online crowdfunding. Many companies such as PledgeMusic, ArtistShare, Kickstarter, Indiegogo, Patreon, RocketHub and Sellaband boast online platforms for musicians to reach out to their fans to pre-sell, market, and distribute music projects including recordings, music videos, and concerts. However, PledgeMusic declared bankruptcy recently. Patreon, a US based company, helps musicians to allow their fans to become active participants through a monthly membership. Patreon's business model includes allowing artists to receive monthly payments for their work, paying their bills using their regular revenue streams. Kickstarter, another American company, is a global crowdfunding platform. Kickstarter has received more than $\$ 4.6$ billion in pledges from 17.2 million backers to fund 445,000 projects, such as films, music, stage shows, comics, journalism, video games, technology, publishing, and food-related projects (Kickstarter, 2020).

Several business models have also evolved to transform music production to benefit performers, composers, and technicians. The technology to create, perform music, collect royalties, and financing has matured. Avid, an American technology and multimedia company, has products consisting of video editing software, audio editing software, music notation software, management, and distribution services. Ableton Live, from Germany, is a digital audio workstation designed to be an instrument for live performances as well as a tool for composing, recording, arranging, mixing, and mastering. Musicians can teach music or use those tools to perform.

\section{PRIVACY AND LEGAL CONSIDERATIONS}

Traditional legal considerations for in-person concerts revolve around contractual arrangements between musicians, concert promoters, ticket sellers, and audience members. The Internet of things gives rise to new and varied concerns.

Virtual reality performances by artists give rise to issues of artist integrity and consent. In particular, what rights does the estate of a deceased artist have to create virtual performances of that musician? As technology evolves, it is likely that musicians themselves will seek to constrain the rights to their legacy in ways that reinforce their artistic vision. That may mean that the rights to live music performances are enlarged or constrained in various ways. For example, some musicians may be happy to have holographic images of themselves created, whereas others will not. Musicians can conceivably legally codify these wishes as part of their performance contracts as well as within any contracts with entertainment industry partners that may manage their estates after they are deceased.

Participating in virtual or online worlds also creates legal and privacy issues for audience members. In traditional live concerts issues of consent can be dealt with by the legal verbiage associated with purchasing a ticket. For example, Ticketmaster states that, as live concerts are a public event, ticketholders "have no expectation of privacy with regard to [their] actions or conduct at the event.” (Ticketmaster, 2020). For concerts where audience members view online or through virtual reality, the issue becomes: should privacy rights be analogous to an in-person live concert or should they vary in some ways? To build a sense of community around those who do not attend concerts in person, there may be a push to relax privacy constraints so that audience members are aware of one another's identities and can share their mutual interest in a musician. However, given the potential for unwanted interactions between audience members, some degree of choice about privacy settings would seem desirable (see, for example, Adjerid et al., 2019).

Another legal consideration for remote attendance at concerts involves the rights of participants to record and share recordings with others. For in-person concerts rules about recording have typically being governed by either ticket 


\section{Issues in Information Systems}

Volume 21, Issue 3, pp. 179-188, 2020

policies or the policies of venues where a performance takes place. For those attending a concert remotely they may have an interest in keeping a recording of the experiences to replay for themselves later, or to share with friends. Potentially this has monetary value for musicians - who could charge a "recording" premium for audience members based on what was recorded and who it was going to be shared with. Musicians may, however, have an interest in not having entire performances made widely available as this could be seen as undercutting their own potential to generate revenue from recordings of live concerts.

\section{LIMITATIONS AND FUTURE RESEARCH}

While the term Internet of Things (IoT) has become commonplace in both the vernacular of technologists and the average consumer, implications in terms of explorations with regard to the changes in usage and social norms have been largely overlooked in Information Systems literature. Cisco Systems coined the term the Internet of Everything (IoE) to describe a systems perspective of all interconnected things, which includes the IoT and the multifaceted daily nature of their interactions with society. Cisco futurist, Evans et al. (2013), stated the issue is not the 'things' but rather the "connections among people, process, data, and things," that is at the heart of the Internet of Everything and creates the 'value' for the consumer. As we have demonstrated, the IoMusT has implications for the use of these technologies within the overall system of connected devices. Notably, the IoT has also provided many new opportunities for recording artists. Musicians can take advantage of the Internet and the tools offered by many companies to loosen their dependence on the weakening of the recording labels. The success of the IoMusT further depends on standardizations of the technology that are unrealized in its current state. Interoperability through standards, protocols, and interfaces will drive the success of this new potential industry overall. Security and privacy, which continue to be the topic of discussion for the internet of things will also need serious research (Turchet et al., 2018).

Typically, live music performances provide a positive shared 'community' experience for fans. The use of various immersive technologies to enhance the experience for the participant, provide additional revenue opportunities and provide additional exposure for artists seems like both a linear and logical progression; however, further exploration should be made to explore the human interaction element and potential ecosystem created from this new technology adoption. Hofstede et al, (2010) describes relationships in terms of layers of an onion with familiar or kinship being at the core. How we interact in forming communities of discourse is important for a 'healthy' community wherein social constraints among participants are both understood and abided (Batteau, 2010). Palfery and Glasser (2008) describe how digital natives look differently toward new ecosystem over time outside of the origins of communities of being. Questions that are worthy of further consideration include: What type of communities will the Music Internet of Things (MIoTs) create? Will the creation of the community experience be advantageous to the artists outside of monetization? What detriments to personal interaction could result?

Turkle (2011, 2016) and (Boyd 2015) have highlighted the dangers of 'connectedness,' not only in terms of privacy, but in terms of what we expect from relationships. Perhaps additional technology may appear to enhance the live performance, but in fact, interfere with the closeness and power of a shared experience. While we expect more from each other in personal relationships yet are willing to give way to technology freely without expectation. Boyd (2015) states privacy is not easy or obvious, but requires a certain amount of agency or power in social situations. As a result, questions about 'status' with regard to agency and 'power' in the interactive immersive experience arise. Turkle (2016) found universal agreement that youth are more connected to various devices, and yet the empathy and emotional gap has widened. Engaging with art is what it means to be truly human insofar as it gives meaning to a wider range of often more mundane experiences in life and culture (Behr et al., 2016). While our love affair with technology seems magical we need to be skeptical of the actual connection(s) we are able to make through these technologies; do they have the ability to bring us closer together or further apart?

\section{CONCLUSIONS}

This paper presented many new possibilities for live music performances specifically traditional live concerts, where a musician or group performs for an audience, the production of online live concerts, and the adoption of new business models through the use of the Musical Internet of Things (IoMusT). The primary consideration was the narrow focus of IoMusT as it pertains to live performances as the IoMusT could encompass many areas in music production. A 


\section{Issues in Information Systems}

Volume 21, Issue 3, pp. 179-188, 2020

secondary review of the literature supported the framework for new possibilities. The possibilities for this embedded system technology connected to the Internet provided in this manner were discussed in terms of audience/musician interactions, technology, business models, privacy and legal considerations concluded with considerations for future research. Great opportunities and challenges exist for the new technology intersection particularly in the time of a pandemic and beyond paving the way for additional research, investment, and standardization.

\section{REFERENCES}

Adjerid, I., Acquisti, A., \& Loewenstein, G. (2019). Choice architecture, framing, and cascaded privacy choices. Management Science, 65(5), 2267-2290.

Baker, C. (2017). Virtual, artificial and mixed reality: New frontiers in performance. In 2017 23rd International Conference on Virtual System \& Multimedia (VSMM) (pp. 1-10).

Batteau, A. W. (2010). Technology and culture. Long Grove, IL: Waveland Press, Inc.

Bedrick, B., Lerner, B., Whitehead, B. "The privacy paradox: Introduction", "News Media and the Law", Washington, DC, Volume 22, Issue 2, Spring 1998, pp. 1-3.

Behr, A., Brennan, M., \& Cloonan, M. (2016). Cultural value and cultural policy: some evidence from the world of live music. International Journal of Cultural Policy, 22(3), 403-418.

Bennett, L. (2012). Patterns of listening through social media: online fan engagement with the live music experience. Social Semiotics, 22(5), 545-557.

Billboard Staff. (2020, May 8). Coronavirus: Ongoing List of Virtual Concerts \& Livestreams. Retrieved May 9, 2020, from https://www.billboard.com/articles/columns/pop/9335531/coronavirus-quarantine-music-events-onlinestreams

Black, G. C., Fox, M. A., \& Kochanowski, P. (2007). Concert tour success in North America: An examination of the top 100 tours from 1997 to 2005. Popular Music and society, 30(2), 149-172.

Boyd, D. (2014). It's complicated: The social lives of networked teens. Yale University Press.

Byam, N.K. (2007). The new shape of online community: The example of Swedish independent music fandom. First Monday, 12(8). August 2007.

Caulfield, K. (2012, April 26). Tupac's Virtual Coachella Appearance Spurs Huge Sales Bump. Retrieved May 9, 2020, from https://www.billboard.com/articles/news/489895/tupacs-virtual-coachella-appearance-spurs-hugesales-bump

Dieck, M. C. tom, \& Jung, T. (2019). Augmented reality and virtual reality: the power of Ar and Vr for business.

Cham, Switzerland: Springer.

Dellyana, D., Simatupang, T. M., \& Dhewanto, W. (2017). Business model types associated with network structure changes in the music industry. International Journal of Business Innovation and Research, 13(1), 112-129.

Drecolias, M. (2014). Tupac and beyond: The implications of the Tupac hologram on copyright and the right of publicity and what it may mean for the future of music. Retrieved from https://scholarship.shu.edu/student_scholarship/427

Earl, P. E. (2001). Simon's travel theorem and the demand for live music. Journal of Economic Psychology, 22(3), 335-358. 
Elvezio, C., Amelot, P., Boyle, R., Wes, C. I., \& Feiner, S. (2018, October). Hybrid UIs for Music Exploration in AR and VR. In 2018 IEEE International Symposium on Mixed and Augmented Reality Adjunct (ISMAR-Adjunct) (pp. 411-412).

Evans, D., Bullotta, R., Evans, D., \& Leung, H. (2013, August 27). Why Connections (not Things) Will Change the World. Retrieved April 10, 2020, from http://blogs.cisco.com/ioe/why-connections-not-things-will-change-theworld/

Fox, M. (2004). E-commerce business models for the music industry. Popular Music and Society, 27(2), 201-220.

Gandolfi, E. (2018). Virtual Reality and Augmented Reality. Retrieved May 30, 2020, from https://www.academia.edu/38550902/Virtual_Reality_and_Augmented_Reality

Ganti, A. (2020, March 27). How Does Fortnite Make Money? Retrieved May 15, 2020, from https://www.investopedia.com/tech/how-does-fortnite-make-money/

Gartenberg, C. (2020, April 28). Facebook is adding the option to charge for access to live streams. Retrieved May 9, 2020, from https://www.theverge.com/2020/4/28/21239863/facebook-live-paid-video-charge-stream-accessevents

Gotrich, L. (2020, March 17). A List Of Live Virtual Concerts To Watch During The Coronavirus Shutdown. Retrieved May 9, 2020, from https://www.npr.org/2020/03/17/816504058/a-list-of-live-virtual-concerts-towatch-during-the-coronavirus-shutdown

Greenburg, Z. O. M. (2020, March 19). Coronavirus Lockdown Gives Fading Concert Streaming Startup Stageit One Last Chance. Retrieved May 28, 2020, from https://www.forbes.com/sites/zackomalleygreenburg/2020/03/18/zombie-jamboree-for-a-struggling-livestreamstartup-coronavirus-lockdown-offers-one-last-chance/\#d6fa9dd5e242

Greengard, S. (2015). The internet of things. Cambridge: MIT Press.

Hofstede, G., Hofstede, G. J., \& Minkov, M. (2010). Cultures and organizations: Software of the mind : Intercultural cooperation and its importance for survival (Revis and expand 3rd ed.). New York: McGraw-Hill.

Hood, V., Knapp, M., \& Griliopoulos, D. (2020, March 24). Best VR games 2020: the top virtual reality games to play right now. Retrieved May 15, 2020, from https://www.techradar.com/best/the-best-vr-games

Hviid, M., Izquierdo-Sanchez, S., \& Jacques, S. (2018). Digitalisation and Intermediaries in the Music Industry: The Rise of the Entrepreneur. SCRIPTed, 15, 242.

Khalid, A. (2020, March 30). Twitch is a home for the world we've lost under quarantine. Retrieved May 25, 2020, from https://qz.com/1828586/twitch-is-a-home-for-the-world-weve-lost-under-quarantine/

Kickstarter (2020). Kickstarter Stats. Retrieved from https://www.kickstarter.com/help/stats on May 10, 2020.

Kulczynski, A., Baxter, S., \& Young, T. (2016). Measuring motivations for popular music concert attendance. Event Management, 20(2), 239-254.

Lab, W. B. (2017, July 10). Live Concerts Take the Virtual Out of Virtual Reality. Retrieved May 18, 2020, from https://www.wired.com/brandlab/2017/07/live-concerts-take-virtual-virtual-reality/

Mallin, R. R. (2018). Retrieved from https://repositories.lib.utexas.edu/bitstream/handle/2152/67681/MALLINTHESIS-2018.pdf?sequence $=1$ 
Martoccio, A. (2020) Prince Estate Announces 'Prince and the Revolution: Live' Streaming Event. Rolling Stone, May 12, at https://www.rollingstone.com/music/music-news/prince-estate-live-event-youtube-998198/

Messenger, H. (2018). Live and in person: how artists are capitalizing on consumers' shifting musical tastes. CNBC, Retrieved from https://www.cnbc.com/2018/08/10/citi-research-the-music-industry-will-consolidate.html on May 14, 2020.

Moelants, D., Demey, M., Grachten, M., Wu, C. F., \& Leman, M. (2012). The influence of an audience on performers: a comparison between rehearsal and concert using audio, video and movement data. Journal of New Music Research, 41(1), 67-78.

Palfrey, J., \& Gasser, U. (2008). Born digital: Understanding the first generation of digital natives. New York, Basic Books.

Persefoni, K., \& Tsinakos, A. (2015). Use of Augmented Reality in terms of creativity in School learning. In Make2Learn 2015 workshop at ICEC’15 (pp. 45-53). New Heaven, CT: CEUR Workshop Proceedings

Rogers, S. (2020, January 27). Will 2020 Be The Year The Music Industry Fully Adopts Immersive Tech? Retrieved May 18, 2020, from https://www.forbes.com/sites/solrogers/2020/01/24/will-2020-be-the-year-the-musicindustry-fully-adopts-immersive-tech/\#72c61d673658

Rubin, P. (2019, February 5). 'Fortnite' Held a Marshmello Concert-and It's the Future of the Metaverse. Retrieved May 18, 2020, from https://www.wired.com/story/fortnite-marshmello-concert-vr-ar-multiverse/

Schmalstieg, D., \& Höllerer, T. (2016). Augmented reality: Principles and practice. Boston: Addison-Wesley.

Shah, A. (2019) List of Songs Rolling Stones Have Played by Request on 2019 Tour, August 15, at https://www.setlist.fm/news/08-19/list-of-songs-rolling-stones-have-played-by-request-on-2019-tour2bd6b06a

Shanley, P. (2020, April 27). Travis Scott's Fortnite Concert Drew 12 Million Viewers. Retrieved May 9, 2020, from https://www.billboard.com/articles/columns/hip-hop/9366303/travis-scott-fortnite-in-game-concert-draws-12million-viewers

Steele, A. (2019). Why Concert Tickets Are So Expensive. Wall Street Journal, December 26,at https://www.wsj.com/articles/why-concert-tickets-are-so-expensive-11577371024

Ticketmaster, Purchase Policy, at https://help.ticketmaster.com/s/article/Purchase-Policy?language=en_US

Tong, Y., She, J., \& Meng, R. (2016). Bottleneck-aware arrangement over event-based social networks: The max-min approach. World Wide Web, 19(6), 1151-1177.

Tsukayama, H. (2012, April 18). How the Tupac 'hologram' works. Retrieved May 9, 2020, from https://www.washingtonpost.com/business/technology/how-the-tupac-hologram-works/2012/04/18/gI

Turchet, L., Fischione, C., Essl, G., Keller, D., \& Barthet, M. (2018). Internet of Musical Things: Vision and Challenges. IEEE Access, 6, 61994-62017.

Turkle, S. (2016). Reclaiming conversation: The power of talk in a digital age. New York, New York: Penguin Books.

Turkle, S. (2011). Alone together: Why we expect more from technology and less from each other. New York: Basic Books. 


\section{Issues in Information Systems}

Volume 21, Issue 3, pp. 179-188, 2020

Webb, K. (2019, October 5). Ninja's move to Mixer brought more streamers to Microsoft's platform - but not more viewers. Retrieved May 30, 2020, from https://www.businessinsider.com/ninja-brought-more-streamers-tomixer-not-more-viewers-2019-10

Webster, E. (2012). “One More Tune!” The Encore Ritual in Live Music Events. Popular Music and Society, 35(1), 93-111.

Westgate, C. J. (2020). Popular Music Fans and the Value of Concert Tickets. Popular Music and Society, 43(1), 5777. 